\title{
MINIMALISASI BIAYA SISTEM DENGAN PEMILIHAN PENGHANTAR JARINGAN DISTRIBUSI MENGGUNAKAN PSO
}

\author{
${ }^{1}$ Risnandar, M.A. \\ ${ }^{1}$ Program Studi Teknik Elektro, Fakultas Teknik, Universitas Muhammadiyah \\ Tasikmalaya, Indonesia \\ e-mail: aris_elektro@umtas.ac.id
}

\begin{abstract}
Abstrak
Pemilihan penghantar memerlukan adanya pertimbangan teknis maupun pertimbangan ekonomi. Hal ini merupakan sebuah permasalahan dalam perencanaan jaringan distribusi tenaga listrik. Proses perencanaan tersebut seringkali dilakukan secara manual sehingga memerlukan perhitungan yang rumit. Particle Swarm Optimization (PSO) digunakan sebagai alat bantu dalam pemecahan masalah pemilihan penghantar pada jaringan distribusi. PSO banyak digunakan dalam pencarian solusi matematis khusunya bidang optimasi, namun proses pencarian solusi global sulit ditemukan sehingga diperlukan modifikasi dalam penggunaan metode ini. Metode PSO yang digunakan dalam penelitian ini yaitu pencarian solusi dengan memasukkan solusi sebelumnya ke dalam inisialisasi partikel pada tahapan selanjutnya. Dengan adanya penambahan proses tersebut, maka solusi yang diperoleh menjadi lebih baik. Hasil yang diperoleh dari penelitian ini menunjukkan bahwa luas penampang penghantar yang besar pada jaringan distribusi tidak mengakibatkan biaya sistem yang mahal.
\end{abstract}

Kata kunci: Particle Swarm Optimization (PSO), pemilihan penghantar, jaringan distribusi tenaga listrik, total biaya sistem.

\begin{abstract}
Conductor selection requires the technical and economic considerations. This condition is a problem in power distribution system planning. Conductor selection usually is often done manually so that it requires a complex calculation. Particle Swarm Optimization (PSO) is used in solving conductor selection in distribution system. PSO used in find the solutions in mathematical optimization, but in process of finding global solutions has difficulty in find the solution so that modifications in this method is required. PSO used for finding a solution by using previous solutions into particles initialization at a next step. With the addition of the process, then the obtained solution is better. Results in this paper shows that a large conductor cross-sectional area in the distribution system does not result in an expensive system cost.
\end{abstract}

Keywords: Particle Swarm Optimization (PSO), conductor selection, distribution system, total cost.

\section{PENDAHULUAN}

Penghantar pada sebuah jaringan distribusi khususnya distribusi primer digunakan untuk menyalurkan energi listrik dari gardu induk ke pusat-pusat beban.

Pemilihan penghantar hendaknya memiliki pertimbangan teknis utama diantaranya kemampuan hantar arus dari penghantar dan jatuh tegangan akibat penyaluran energi listrik tersebut (Taofeq, Anggoro, \& Arfianto, 2013). Dengan adanya pertimbangan teknis tersebut, maka pemilihan penghantar pada jaringan distribusi mengakibatkan perbedaan harga penghantar untuk masing-masing jenis penghantar yang akan digunakan.
Selain itu, dalam penyaluran energi listrik selalu terjadi rugi-rugi daya akibat resistansi dari penghantar itu sendiri (Waluyo, Soenarjo, \& Akbar, 2012). Sehingga dengan adanya rugi-rugi daya tersebut biaya yang dikeluarkan dalam penyaluran energi listrik menjadi lebih besar.

Kondisi seperti ini mengakibatkan adanya perbedaan biaya sistem yang terdiri dari biaya modal, yaitu biaya yang harus dikeluarkan dalam pembelian penghantar dan biaya operasional, yaitu biaya akibat adanya rugi-rugi daya dalam penyaluran energi listrik tersebut. Proses pemilihan penghantar yang baik, diperlukan 
pertimbangan teknis dan ekonominya (Suheta, Kotima, \& Zaman, 2009).

Biaya sistem tersebut dapat diminimalisir dengan pemilihan penghantar yang tepat. Namun pemilihan penghantar tersebut memiliki kesulitan dimana jika kita memiliki $t$ buah jenis penghantar yang dapat digunakan pada masing-masing saluran dan sebuah sistem tersebut memiliki $L$ buah saluran, maka solusi terbaik pemilihan penghantar tersebut memiliki $t^{L}$ buah kemungkinan. Hal tersebut akan sangat sulit ditentukan dengan cara manual dan memerlukan waktu yang cukup lama.

Saat ini pemilihan penghantar biasa dilakukan dengan cara manual (Suheta, Kotima, \& Zaman, 2009), dimana pemilihan penghantar hanya dilandasi aspek teknis saja.

Agar pemilihan penghantar dilakukan dengan efektif yaitu dengan mempertimbangkan aspek teknis dan aspek ekonomi sekaligus, maka penelitian ini menggunakan alat bantu berupa metode optimasi Particle Swarm Optimization (PSO). Metode PSO dapat diaplikasikan dalam proses pencarian solusi matematis yang rumit dan tidak membutuhkan proses komputasi yang rumit (Tuegeh, Soeprijanto, \& Purnomo, 2009). Namun penentuan parameter PSO yang digunakan sangat mempengaruhi proses pencarian solusi, sehingga diperlukan percobaan-percobaan dalam menentukan parameter PSO tersebut (Risnandar, 2015). Pemilihan parameter yang kurang tepat tersebut mengakibatkan proses pencarian sulit untuk memperoleh solusi global dari sebuah permasalahan.

\section{Biaya Sistem}

Biaya sistem dalam penelitian ini didefiniskan sebagai biaya modal dan biaya operasional akibat rugi-rugi daya.

\section{Biaya Modal}

Biaya modal dalam penelitian ini yaitu biaya yang harus dikeluarkan dalam membeli penghantar sehingga dapat ditulis:

$$
C_{i n v(t)}=\frac{n \times A_{(t)} \times l \times \lambda \times 1000}{t_{o p(t)} \times 8760}
$$

Dimana:

$$
\begin{aligned}
& C_{i n v(t)}=\text { biaya investasi penghantar } t \\
& \text { (Rp/jam) } \\
& n=\text { jumlah inti pada penghantar } t \\
& A_{(t)} \quad=\text { luas penampang penghantar } t \\
& \left(\mathrm{~mm}^{2}\right) \\
& l=\text { panjang penghantar }(\mathrm{km}) \\
& \lambda=\text { harga satuan penghantar } t \\
& \text { (Rp/inti/mm²/m) } \\
& t_{o p(t)}=\text { waktu operasional penghantar } t \\
& \text { (tahun) }
\end{aligned}
$$

Waktu operasional penghantar sangat mempengaruhi harga investasi penghantar (Rp/jam) dimana semakin lama waktu operasional, maka biaya investasi penghantar akan semakin murah.

\section{Biaya Operasional}

Biaya operasional dalam penelitian ini yaitu biaya akibat adanya rugi-rugi daya sehingga dapat ditulis:

$$
C_{\text {loss }(t)}=P_{\text {loss }(t)} \times \rho
$$

Dimana:

$$
\begin{aligned}
& C_{l o s s(t)}=\text { biaya rugi-rugi daya akibat } \\
& \text { penghantar } t \text { (Rp/jam) } \\
& P_{\text {loss }(t)}=\text { rugi-rugi daya akibat penghantar } \\
& t(\mathrm{~kW}) \\
& \rho \quad=\text { tarif listrik }(\mathrm{Rp} / \mathrm{kWh})
\end{aligned}
$$

Pemeliharaan penghantar dalam penelitian ini tidak diperhitungkan, sehingga biaya operasional hanya merupakan biaya akibat rugi-rugi daya saja.

\section{Particle Swarm Optimization (PSO)}

Metode PSO banyak digunakan dalam sebuah pencarian solusi matematis yang rumit dimana metode tersebut terinspirasi dari perilaku sosial binatang. Pergerakan pencarian solusi mengadopsi tentang perilaku posisi partikel dalam sebuah populasi. Pergerakan tersebut dipengaruhi oleh lingkungannya berupa pembelajaran terhadap dirinya sendiri (cognitive learning) dan pembelajaran terhadap lingkungannya (social learning) (Purnomo, 2014).

Secara matematis, proses pencarian posisi partikel tersebut dipengaruhi oleh kecepatan partikel $v$, yaitu:

$$
v_{p}^{k+1}=v_{p}^{k}+c 1 r 1\left(P b_{p}^{k}-x_{p}^{k}\right)+c 2 r 2\left(G b^{k}-x_{p}^{k}\right)
$$

Dimana: 


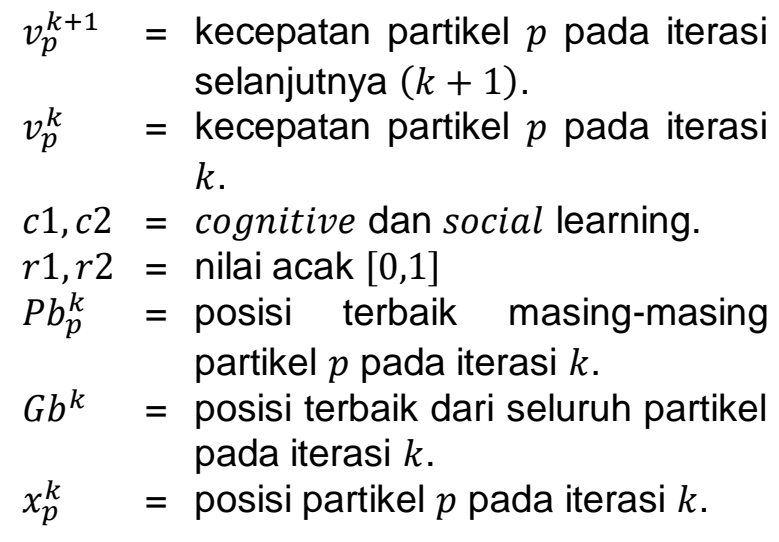

Pemilihan nilai parameter $c 1$ dan $c 2$ akan mempengaruhi pergerakan partikel dalam pencarian solusi, dimana nilai $c 1$ dan c2 yang besar mengakibatkan jarak antara masing-masing partikel menjadi lebih jauh sehingga proses pencarian solusi menjadi kurang teliti.

Selain itu, dalam proses pencarian solusi tersebut, kecepatan partikel hendaknya dibatasi agar ruang pencarian solusi tidak terlalu menjauh dan dapat ditulis:

$$
v_{\text {min }} \leq v \leq v_{\text {maks }}
$$

Dimana $v_{\min }$ adalah batas bawah kecepatan partikel dan $v_{\text {maks }}$ adalah batas atas kecepatan partikel.

Selanjutnya posisi partikel yang baru pada setiap iterasi dapat ditulis:

$$
x_{i}^{k+1}=x_{i}^{k}+v_{i}^{k+1}
$$

Dimana $x_{i}^{k+1}$ merupakan posisi partikel $i$ pada iterasi selanjutnya.

Seperti halnya kecepatan, maka posisi partikel pun perlu dibatasi dengan:

$$
x_{\text {min }} \leq x \leq x_{\text {maks }}
$$

Dimana $x_{\min }$ adalah batas bawah posisi partikel dan $x_{\text {maks }}$ adalah batas atas posisi partikel.

\section{Pengkodean}

Operasi PSO hanya dapat dilakukan dalam bentuk matematis, dimana pemilihan penghantar harus diubah ke dalam bentuk matematis. Jenis penghantar yang digunakan pada masing-masing saluran harus direpresentasikan ke dalam bentuk matriks agar pencarian solusi mudah dilakukan. Masing-masing partikel PSO membawa informasi jenis penghantar yang akan digunakan pada masing-masing saluran dimana masing-masing partikel memiliki dimensi sebesar $L$ yaitu jumlah saluran pada sistem distribusi dan dapat ditulis:

$$
x_{p}=\left[\begin{array}{llll}
x_{p 1} & x_{p 2} & \ldots & x_{p L}
\end{array}\right]
$$

Dimana penghantar tipe ke-1 $\leq$ $x_{p 1}, x_{p 2}, \ldots x_{p L} \leq$ penghantar tipe ke- $t$ dan $1,2, \ldots, L$ adalah nomor saluran pada jaringan.

Sehingga bentuk matriks populasi PSO dapat ditulis:

$$
x=\left[\begin{array}{ccc}
x_{11} & \cdots & x_{1 L} \\
\vdots & x_{p q} & \vdots \\
x_{H 1} & \cdots & x_{H L}
\end{array}\right]
$$

Adapun informasi tipe penghantar pada masing-masing saluran tersebut memiliki nilai bulat.

\section{Aliran Daya}

Model jaringan yang sering digunakan pada jaringan distribusi khususnya di Indonesia yaitu model jaringan radial. Sehingga metode aliran daya yang digunakan memiliki kekhasan tersendiri (Kitta, 2003).

Studi aliran daya digunakan untuk mencari aliran daya/arus yang mengalir pada masing-masing saluran dalam sebuah jaringan.

Metode aliran daya daya yang digunakan dalam penelitian ini yaitu metode forward-backward sweep, dimana metode ini menggunakan prinsip hukum Kirchoff untuk perhitungan arus (Novialifiah, Soeprijanto, \& Wibowo, 2014).

Prinsip utama dalam metode ini yaitu yaitu menghitung nilai arus yang mengalir pada masing-masing saluran akibat beban pada masing-masing titik beban, dimana arus pada masing-masing titik beban dapat ditulis:

$$
\bar{I}_{i}=\left(\frac{\bar{S}_{i}}{\bar{V}_{i}}\right)^{*}
$$

Dimana:

$\bar{I}_{i}=$ arus beban pada titik beban $i$ 
$\bar{S}_{i}=$ beban pada titik beban $i\left(P_{b}-j Q_{b}\right)$
$\bar{V}_{i}=$ tegangan pada titik beban $i$

Selanjutnya, nilai tegangan pada masing-masing titik beban dihitung melalui persamaan:

$$
\bar{V}_{i}=\bar{V}_{0}-\Delta \bar{U}_{i}
$$

Dimana $\bar{V}_{i}$ adalah tegangan pada masing-masing titik beban dalam sebuah jaringan, $\bar{V}_{0}$ adalah tegangan referensi di gardu induk, dan $\Delta \bar{U}_{i}$ adalah jatuh tegangan total pada masing-masing titik beban.

Secara umum diagram alir dalam metode ini yaitu:

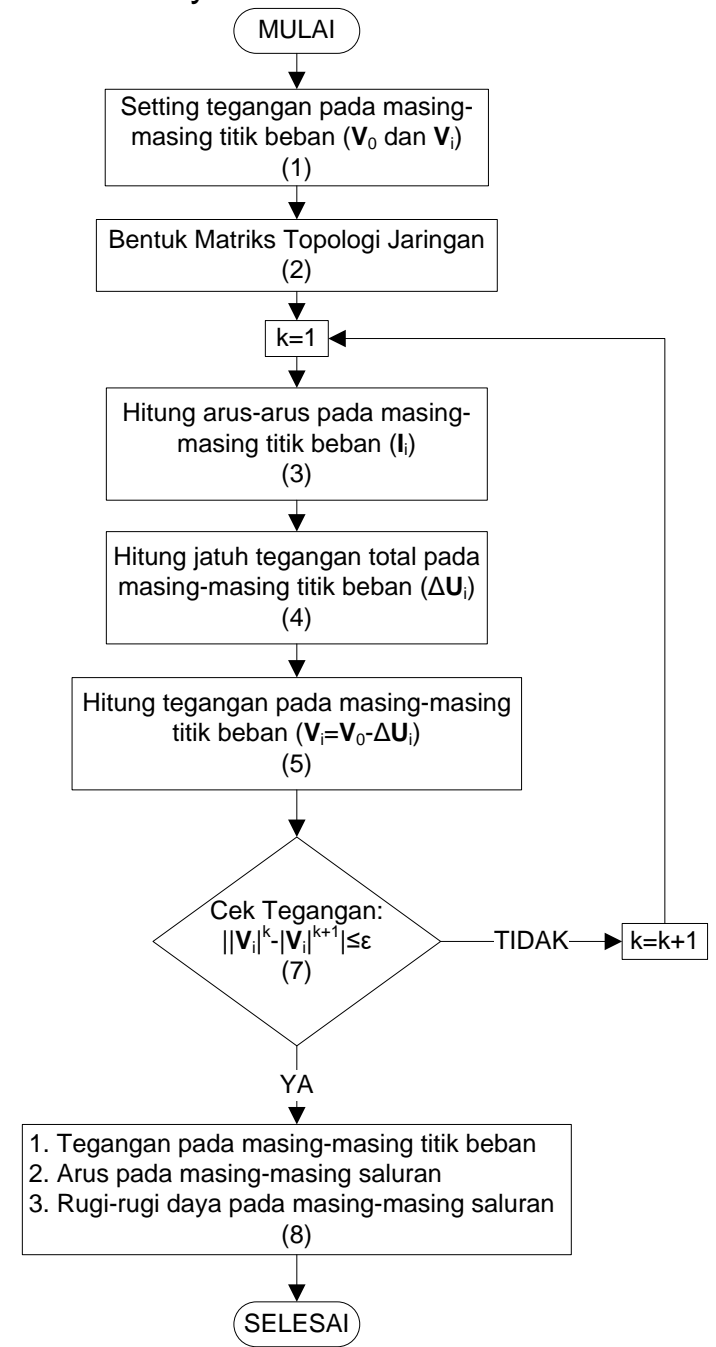

Gambar 1 Diagram Alir Metode Backward-Forward Sweep

Dengan diperolehnya jatuh tegangan pada masing-masing titik beban dan arus beban pada masing-masing titik beban, maka rugi-rugi daya pada masing-masing saluran akan mudah ditemukan.

\section{Fungsi Objektif}

Permasalahan dalam penelitian ini yaitu biaya sistem dimana hal tersebut dipengaruhi oleh biaya investasi penghantar dan biaya akibat rugi-rugi daya. Dengan pemilihan penghantar yang kurang tepat, maka biaya sistem menjadi besar dan tentu akan merugikan pihak produsen listrik.

Penelitian ini dimaksudkan untuk meminimalkan biaya sistem dimana biaya sistem yang dihitung setiap satu jam dan dapat ditulis:

$$
\min C_{s i s}=\sum_{j=a}^{L} C_{i n v(j, t)}+\sum_{j=a}^{L} C_{l o s s(j, t)}
$$

Dimana:

$$
\begin{aligned}
C_{\text {sis }}= & \text { total biaya sistem }(\mathrm{Rp} / \mathrm{jam}) \\
C_{i n v(j, t)=} & \text { biaya investasi penghantar pada } \\
& \text { cabang } j \text { akibat penggunaan } \\
& \text { penghantar } t(\mathrm{Rp} / \mathrm{jam}) \\
C_{\text {loss }(j, t)=} & \text { biaya rugi-rugi daya pada } \\
& \text { cabang } j \text { akibat penggunaan } \\
& \text { penghantar } t(\mathrm{Rp} / \mathrm{jam}) \\
= & \text { jumlah cabang pada sistem }
\end{aligned}
$$

\section{METODE}

Penelitian ini dilakukan melalui sebuah simulasi pada sebuah jaringan distribusi radia. Adapun model jaringan yang digunakan yaitu model jaringan IEEE 12 titik beban yang telah dimodifikasi sesuai dengan kondisi lapangan (Risnandar, 2015).

Gambar 2 menunjukkan masingmasing titik beban $K_{i}$ terhubung satu sama lain melalui sebuah saluran $j$. Kondisi seperti ini mengakibatkan adanya arus beban yang berbeda pada masing-masing saluran tersebut sehingga rugi-rugi daya pada masing-masing beban menjadi beragam. 


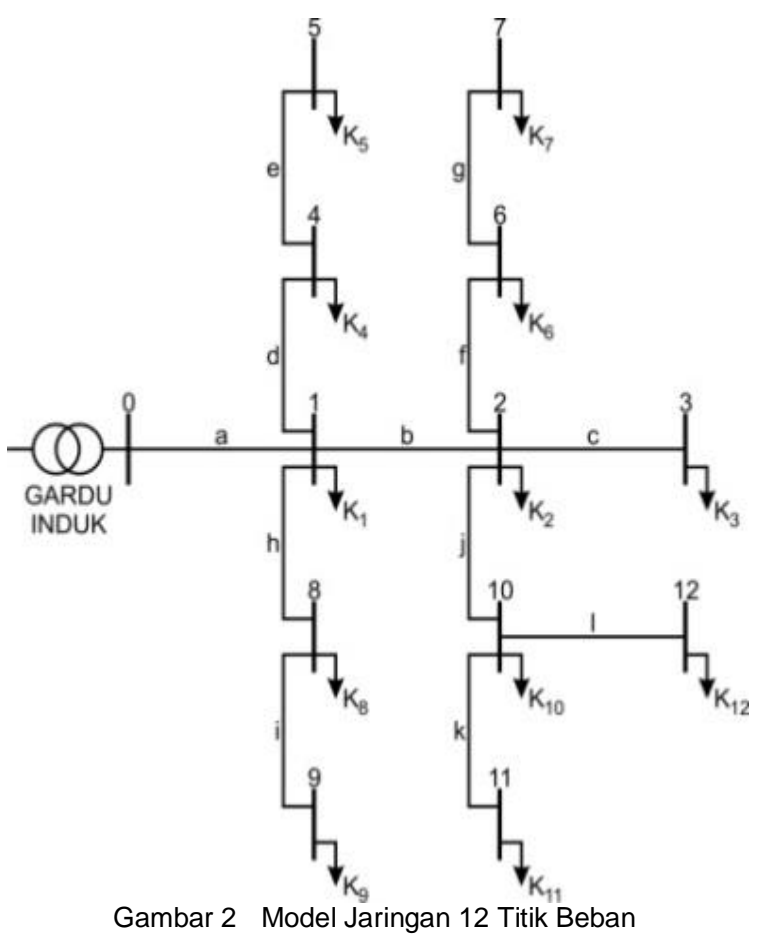

Masing-masing titik beban memiliki posisi yang berbeda, dimana masingmasing titik beban tersebut dihubungkan oleh sebuah saluran $j$. Kondisi ini mengakibatkan jarak yang berbeda untuk masing-masing saluran tersebut.

Panjang masing-masing saluran dalam penelitian ini ditentukan secara acak dimana hal tersebut disesuaikan dengan kondisi sebenarnya di lapangan pada sebuah sistem distribusi tenaga listrik Adapun panjang masing-masing saluran yang digunakan dalam penelitian ini ditentukan sebagai berikut:

Tabel 1 Data Saluran

\begin{tabular}{cccc}
\hline $\begin{array}{c}\text { Cabang/ } \\
\text { Saluran }\end{array}$ & $\begin{array}{c}\text { Jarak } \\
(\mathbf{k m})\end{array}$ & $\begin{array}{c}\text { Cabang/ } \\
\text { Saluran }\end{array}$ & $\begin{array}{c}\text { Jarak } \\
\mathbf{( k m )}\end{array}$ \\
\hline $\mathrm{a}$ & 1.2 & $\mathrm{~g}$ & 0.8 \\
$\mathrm{~b}$ & 2.6 & $\mathrm{~h}$ & 2.4 \\
$\mathrm{c}$ & 2.2 & $\mathrm{i}$ & 1.9 \\
$\mathrm{~d}$ & 1.4 & $\mathrm{j}$ & 1.8 \\
$\mathrm{e}$ & 1.3 & $\mathrm{k}$ & 0.7 \\
$\mathrm{f}$ & 1.5 & $\mathrm{I}$ & 1.6 \\
\hline
\end{tabular}

Jenis penghantar yang biasa digunakan dalam penyaluran energi listrik khususnya SKTM (saluran kabel tegangan menengah) yaitu kabel dengan penghantar alumunium dan berisolasi XLPE. Pemilihan kabel jenis ini sering digunakan karena harganya relatif murah dan memiliki kualitas baik.

Penghantar jenis ini memiliki spesifikasi teknis yang berbeda untuk masing-masing luas penampangnya. Adapun spesifikasi teknis jenis penghantar yang digunakan dalam penelitian ini mengacu pada sebuah produsen kabel (Havells India Ltd,, 2013) dimana spesifikasi teknis penghantar ditunjukkan sebagai berikut:

Tabel 2 Spesifikasi Penghantar yang Digunakan

\begin{tabular}{cccc}
\hline Tipe & $\begin{array}{c}\mathbf{R}(\boldsymbol{\Omega} / \\
\boldsymbol{k m})\end{array}$ & $\begin{array}{c}\mathbf{X}(\boldsymbol{\Omega} / \\
\boldsymbol{k m})\end{array}$ & $\begin{array}{c}\text { Luas } \\
\text { Penampang } \\
\left(\mathbf{m m}^{\mathbf{2}}\right)\end{array}$ \\
\hline 1 & 1.540 & 0.148 & 25 \\
2 & 1.110 & 0.141 & 35 \\
3 & 0.820 & 0.132 & 50 \\
4 & 0.567 & 0.125 & 70 \\
5 & 0.410 & 0.119 & 95 \\
\hline
\end{tabular}

Luas penampang penghantar yang digunakan ditentukan berdasarkan kemampuan arus masing-masing penghantar tersebut dimana arus beban pada model jaringan ini masih dapat disalurkan oleh penghantar tersebut.

Selain itu masing-masing jenis penghantar tersebut memiliki harga yang berbeda-beda dimana harga tersebut ditentukan oleh luas penampang pebghantarnya. Harga penghantar yang digunakan dalam penelitian ini mengacu pada harga pasaran kabel tegangan menengah yaitu sekitar Rp 1.600,/inti $/ \mathrm{mm}^{2} / \mathrm{m}$.

Arus beban sangat ditentukan kondisi beban dimana beban-beban tersebut akan mempengaruhi kondisi jaringan secara keseluruhan. Beban yang digunakan dalam penelitian ini ditentukan secara acak seperti halnya panjang saluran. Adapun data beban yang digunakan dalam penelitian ini ditentukan sebagai berikut:

Tabel 3 Data Beban

\begin{tabular}{cccccc}
\hline Node & $\begin{array}{c}\mathbf{S} \\
(\mathbf{k V A})\end{array}$ & $\begin{array}{c}\mathbf{P F} \\
(\mathbf{c o s} \boldsymbol{\varphi})\end{array}$ & Node & $\begin{array}{c}\mathbf{S} \\
(\mathbf{k V A})\end{array}$ & $\begin{array}{c}\mathbf{P F} \\
(\mathbf{c o s} \boldsymbol{\varphi})\end{array}$ \\
\hline 1 & 200 & 0.95 & 7 & 120 & 0.90 \\
2 & 320 & 0.75 & 8 & 320 & 0.85 \\
3 & 480 & 0.65 & 9 & 320 & 0.75 \\
4 & 320 & 0.85 & 10 & 320 & 0.95 \\
5 & 200 & 0.85 & 11 & 320 & 0.90
\end{tabular}




\begin{tabular}{rrrrrc}
6 & 200 & 0.90 & 12 & 480 & 0.95 \\
\hline & Energi & listrik pada & sebuah jaringan
\end{tabular}
distribusi diperoleh dari produsen listrik dimana di Indonesia biaya energi ditentukan oleh pemerintah. Dengan adanya rugi-rugi daya pada sebuah jaringan distribusi, maka biaya tersebut tetap muncul dan ditanggung oleh pihak produsen. Kondisi seperti ini menimbulkan kerugian dalam aspek ekonomi. Biaya energi tersebut diatur dalam tarif dasar listrik (TDL) yang mengacu pada (Permen ESDM Nomor 28 Tahun 2016, 2016).

Jenis tarif yang digunakan dalam penelitian ini mengacu pada jenis tarif golongan industri tegangan menengah. Tarif jenis ini dibedakan berdasarkan tarif pada waktu beban puncak (WBP) dan tarif luar waktu beban puncak (LWBP).

Untuk WBP tarif listrik dikenakan sebasar $K \times \mathrm{Rp} 1.115,-/ \mathrm{kWh}$ dan pada LWBP tarif listrik yang dikenakan sebesar Rp 1.115,-. $K$ merupakan faktor perbandingan antara harga WBP dan LWBP sesuai dengan karakteristik beban sistem kelistrikan setempat dan ditetapkan oleh Direksi PT PLN (Persero) dalam hal ini penyedia listrik. Dimana nilai $K$ berkisar antara 1.4 s.d 2.

Asumsi yang digunakan dalam penelitian ini memiliki beban puncak dari pukul 17.00 - 22.00 sehingga dengan mengasumsikan $K=1.4$ maka tarif listrik rata-rata sebesar Rp 1.207,-/kWh dan saat $K=2$, maka tarif listrik rata-rata sebesar $\mathrm{Rp}$ $1.347,-/ k W h$. Dengan adanya interval harga tersebut maka dalam memudahkan perhitungan, tarif listrik yang digunakan dalam penelitian ini yaitu sebesar $R p$ 1.300,/kWh.

Proses pencarian solusi yang dilakukan dalam penelitian ini yaitu menggunakan metode PSO, dimana masing-masing partikel membawa informasi tipe penghantar yang akan digunakan pada masing-masing saluran dengan dimensi sebesar $L$. Proses pencarian solusi tersebut ditentukan melalui proses berikut:

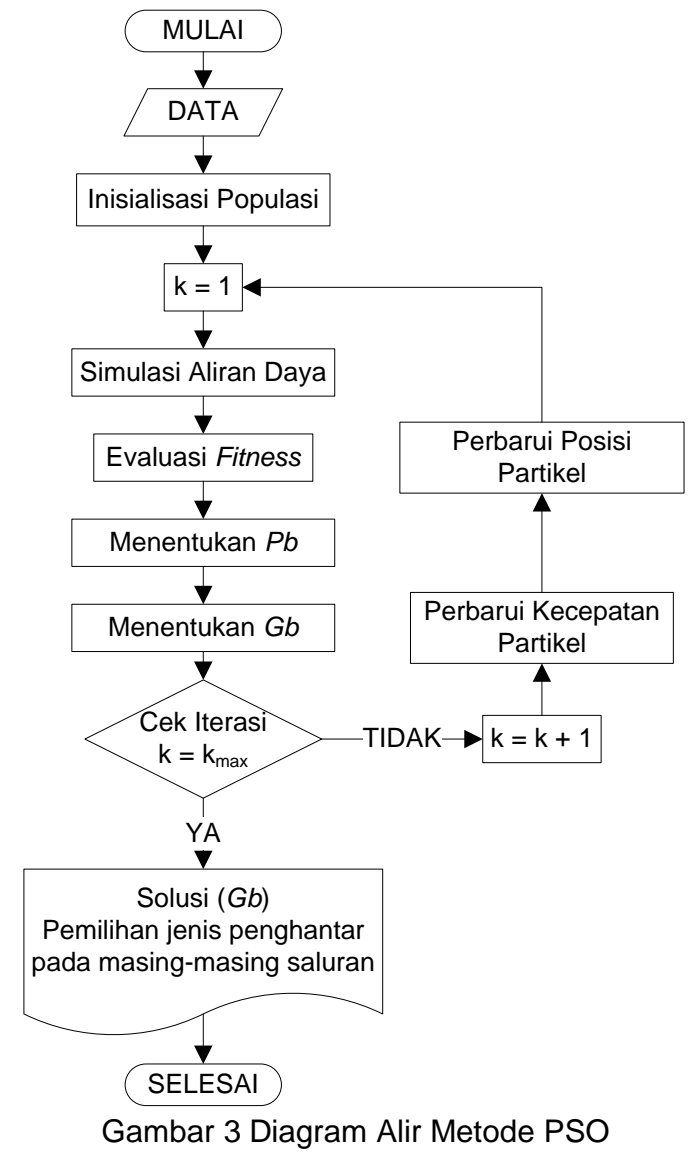

Inisialisasi partikel dimaksudkan untuk meberikan informasi jenis penghantar yang akan digunakan dalam masing-masing saluran dan ditentukan secara acak. Selanjutnya simulasi aliran daya dilakukan berdasarkan informasi yang dibawa oleh masing-masing partikel tersebut berupa jenis penghantar yang digunakan pada masing-masing saluran. Setelah dilakukan simulasi aliran daya, maka perhitungan nilai objektif atau nilai fitness dapat dilakukan dengan mudah.

Setelah dilakukan perhitungan secara terus-menerus hingga iterasi $k_{\text {maks }}$, maka proses pencarian solusi dihentikan dan diperoleh solusi $G b$ yang merepresentasikan jenis penghantar terbaik pada masingmasing saluran.

Agar pencarian solusi tersebut lebih optimal, maka digunakan parameterparameter sebagai berikut:

Jumlah Partikel $(H) \quad: 20$

Dimensi Partikel $(D) \quad: 12$

Iterasi Maksimum $\left(k_{\max }\right): 100$

$c 1, c 2 \quad: 1$

$v_{\max }: 2$

$v_{\min }:-2$ 
Jumlah partikel yang digunakan dalam pencarian solusi menggunakan 20 buah partikel, dimana jumlah tersebut cukup untuk mewakili pencarian solusi tersebut (Risnandar, 2015). Dimensi partikel merupakan jumlah saluran pada jaringan distribusi.

Proses yang dilakukan berdasarkan Gambar 3 Diagram Alir Metode

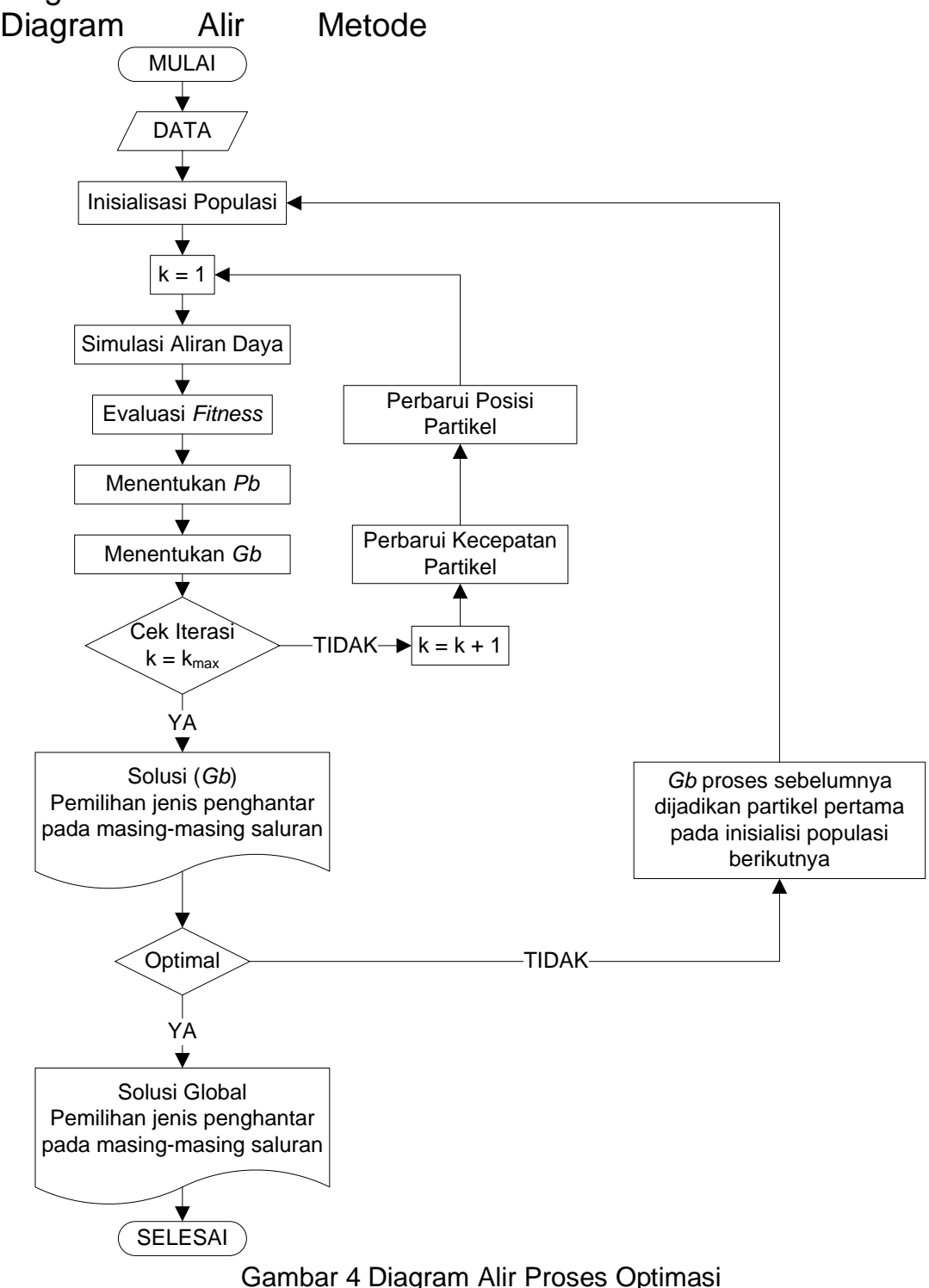

Setelah diperoleh solusi $G b$, maka $G b$ tersebut dimasukkan ke dalam insialisasi partikel selanjutnya dan dapat ditulis:

$$
x=\left[\begin{array}{ccc}
G b_{1} & \cdots & G b_{L} \\
x_{21} & \cdots & x_{2 L} \\
\vdots & x_{p q} & \vdots \\
x_{H 1} & \cdots & x_{H L}
\end{array}\right]
$$

Selanjutnya proses pencarian dihentikan saat solusi dianggap optimal mengalami permasalahan baru dimana solusi tersebut mengalami perubahan solusi saat dilakukan simulasi ulang.

Agar pencarian solusi lebih efektif, maka proses berikutnya dilakukan proses yang mengacu pada Error! Reference source not found.. 
belum memiliki penghantar, sehingga diperlukan pemilihan jenis penghantar yang tepat agar mendapatkan biaya sistem yang minimal.

\section{Perhitungan Manual}

Kondisi pertama, simulasi dilakukan tanpa menggunakan metode PSO dimana pemilihan tipe penghantar dilakukan secara manual yaitu seluruh saluran menggunakan tipe penghantar yang sama.

Pada saat masing-masing saluran menggunakan tipe penghantar $t$, maka biaya sistem dapat ditunjukkan sebagai berikut:

Tabel 4 Pemilihan Tipe Penghantar Secara Manual

\begin{tabular}{cc}
\hline $\begin{array}{c}\text { Tipe } \\
\text { Penghantar }\end{array}$ & $\begin{array}{c}\text { Total Biaya Sistem } \\
\text { (ribu rupiah/jam) }\end{array}$ \\
\hline 1 & 200.78 \\
2 & 153.48 \\
3 & 128.95 \\
4 & 113.38 \\
5 & 113.05 \\
\hline
\end{tabular}

Berdasarkan Tabel 4, maka jenis penghantar yang memberikan total biaya sistem terendah yaitu tipe penghantar 5 yaitu tipe penghantar dengan luas penampang $95 \mathrm{~mm}^{2}$. Hal ini menunjukkan bahwa luas penampang penghantar besar memberikan biaya sistem yang murah dibandingkan menggunakan penghantar dengan luas penampang yang kecil.

\section{Perhitungan dengan Optimasi}

Kondisi kedua, simulasi dilakukan dengan menggunakan metode PSO yang

Tabel 5 Pemilihan Tipe Penghantar Setelah Optimasi telah diperbaiki seperti ditunjukkan pada Error! Reference source not found.. Pencarian solusi yang dilakukan dihentikan pada saat pencarian solusi (percobaan) kelima, dimana proses pencarian solusi tidak mengalami perubahan mulai dari pencarian solusi (percobaan) keempat. Kondisi ini memberikan kesimpulan bahwa proses pencarian solusi dapat dilakukan melalui proses yang ditunjukkan pada Gambar 4.

Adapun hasil simulasi berdasarkan proses pencarian solusi berupa tipe penghantar pada masing-masing saluran ditunjukkan melalui Tabel 5.

Biaya sistem pada masing-masing percobaan ditunjukkan Gambar 5. Hal ini menunjukkan bahwa pencarian solusi mengalami perbaikan pada setiap percobaan berikutnya.

\section{Total Biaya Sistem}

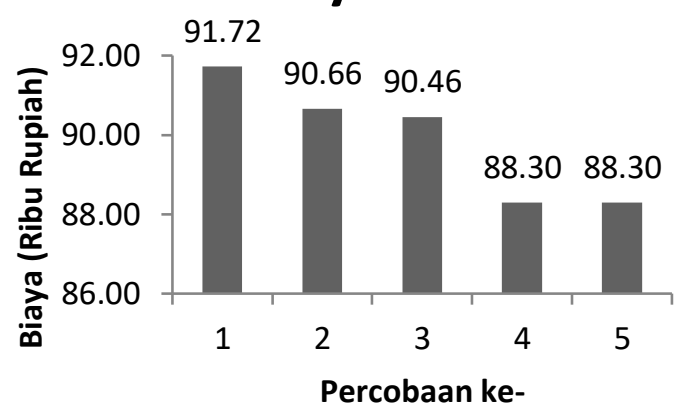

Gambar 5 Biaya Sistem pada Setiap Percobaan

\begin{tabular}{lccccc}
\hline Percobaan ke- & $\mathbf{1}$ & $\mathbf{2}$ & $\mathbf{3}$ & $\mathbf{4}$ & $\mathbf{5}$ \\
\hline Node-1 & 5 & 5 & 5 & 5 & 5 \\
Node-2 & 2 & 4 & 5 & 4 & 4 \\
Node-3 & 1 & 4 & 5 & 2 & 2 \\
Node-4 & 3 & 2 & 5 & 3 & 3 \\
Node-5 & 4 & 2 & 1 & 3 & 3 \\
Node-6 & 3 & 4 & 1 & 2 & 2 \\
Node-7 & 1 & 1 & 4 & 3 & 3 \\
Node-8 & 2 & 2 & 4 & 5 & 5 \\
Node-9 & 5 & 5 & 2 & 2 & 2 \\
Node-10 & 2 & 1 & 5 & 4 & 4 \\
Node-11 & 2 & 2 & 5 & 4 & 4 \\
Node-12 & 3 & 3 & 3 & 4 & 4 \\
\hline $\begin{array}{l}\text { Total Biaya Sistem } \\
\text { (ribu rupiah/ jam) }\end{array}$ & 91.72 & 90.66 & 90.46 & 88.30 & 88.30 \\
\hline
\end{tabular}


Pemilihan penghantar yang tepat mempengaruhi biaya sistem pada jaringan distribusi. Pemilihan penghantar dengan luas penampang besar tidak selalu memberikan biaya sistem yang murah seperti pembahasan sebelumnya, dan sebaliknya. Selain itu pemilihan penghantar dengan metode ini memberikan perbedaan biaya sistem yang cukup signifikan dibandingkan dengan menggunakan jenis penghantar $t$ yang sama pada jaringan distribusi (Gambar 6).

Total Biaya Sistem (ribu rupiah/jam)

113.05

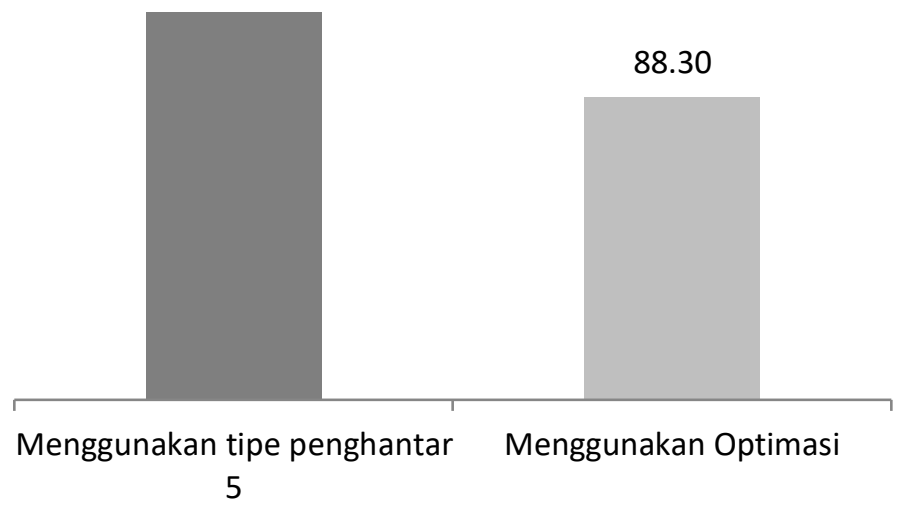

Gambar 6 Total Biaya Sistem Setelah Optimasi
Simulasi dalam penelitian menunjukkan adanya penurunan biaya sistem sebesar $21.90 \%$. Dengan adanya penurunan ini, maka pihak penyedia listrik lebih diuntungkan dengan penggunaan metode ini.

\section{SIMPULAN}

Pemilihan penghantar pada sebuah jaringan distribusi perlu mempertimbangkan aspek teknis dan aspek ekonomi. Penelitian ini menunjukkan bahwa penggunaan metode PSO dapat digunakan dalam pemilihan penghantar jaringan distribusi, dimana hasil yang diperoleh dari metode ini menunjukkan efisiensi yang cukup signifikan.

\section{UCAPAN TERIMA KASIH}

Penulis mengucapkan terima kasih yang sebesar-besarnya kepada Lembaga Penelitian dan Pengabdian Masyarakat (LPPM) Universitas Muhammadiyah Tasikmalaya yang telah mendanai penelitian ini.

\section{DAFTAR PUSTAKA}

Havells India Ltd,. (2013). LT/HT Power \& Control Cables Catalogue . India.

Kitta, I. (2003). Analisa Pemodelan Perhitungan Susut Energi Jaringan Distribusi Listrik. Institut Teknologi Bandung, Sekolah Teknik Elektro dan Informatika. Bandung: Institut Teknologi Bandung.

Novialifiah, R. W., Soeprijanto, A., \& Wibowo, R. S. (2014). Algoritma Aliran Daya untuk Sistem Distribusi Radial dengan Beban Sensitif Tegangan. Jurnal Teknik POMITS , 3 (1), B7-B11.

Permen ESDM Nomor 28 Tahun 2016. (2016, Oktober). Tarif Tenaga Listrik yang Disediakan oleh PT Perusahaan Listrik Negara (Persero) . Jakarta, Indonesia.

Purnomo, H. D. (2014). Cara Mudah Belajar Metode Optimasi Metaheuristik Menggunakan Matlab (Vol. I). Yogyakarta: Gava Media.

Risnandar, M. A. (2015). Optimasi Susunan Fasa Pembebanan Jaringan Distribusi dalam Mengurangi Rugi Daya Menggunakan Particle Swarm Optimization (PSO). Tesis, Institut 
Teknologi Bandung, Sekolah Teknik Elektro dan Informatika, Bandung.

Suheta, T., Kotima, \& Zaman, A. B. (2009). Studi Analisa Pemilihan Kawat Konduktor pada Penyulang Indomie Rungkut di Area Pelayanan dan Jaringan Surabaya Selatan. Seminar Nasional Electrical, Informatics, and It's Educations, (hal. A1-83 - A1-86).

Taofeq, T., Anggoro, B., \& Arfianto, T. (2013). Perancangan Sistem Kelistrikan pada Pusat Listrik Tenaga Minihidro Lapai 2x2000 kW di Sulawesi Tenggara. Jurnal Reka Elkomika , 1 (2), 109-118.

Tuegeh, M., Soeprijanto, \& Purnomo, M. H. (2009). Modified Improved Particle Swarm Optimization for Optimal Generator Scheduling. Seminar Nasional Aplikasi Teknologi Informasi 2009 (SNATI 2009), (hal. 85-90). Yogyakarta.

Waluyo, Soenarjo, \& Akbar, A. A. (2012). Perhitungan Susut Daya pada Sistem Distribusi Tegangan Menengah Saluran Udara dan Kabel. Jurnal Sains dan Teknologi EMAS , 17 (3). 